\title{
Opinion Analysis of Software Developers Working Onsite on Public Sector Software Projects: An Exploratory Study
}

\author{
D. KÖSEOĞLU and O. CHOUSEINOGLOU
}

\begin{abstract}
Among critical stakeholders of software projects developed in public institutions are software developers and project managers affiliated to sub-contractor companies, who are working onsite at the public institutions. The aim of this study is to identify, determine and have an initial understanding regarding how software developers are affected and what are the factors that effect software developers and project managers while working onsite in public software projects. The research is designed as an exploratory and qualitative study. The study participants were 10 software developers, one technical team leader and four project managers, all having long experiences in working on public software projects on client premises. Semistructured interview technique is employed as the data collection method and "content analysis" was applied on the obtained participant responses. Following this analysis, "key content" approach was used to identify the issues to be further considered. It has been determined that the productivity of software developers working onsite at public institutions is low due to intense requests, shortened time to fulfill these requests, and long duration of authorization processes. Moreover, a finding of the study is that the quality of the developed projects and the motivation of the developers are considered to be low for the same aforementioned reasons. Among the foremost causes for these results are the fact that employees work under two different hierarchical structures one in the public institution and one in the software company, more than one managers assign work and there is an authority confusion between organizational units and people in the public institutions.
\end{abstract}

Index Terms - Content analysis, Exploratory study, Onsite employment, Public sector software projects, Software developer motivation.

\section{INTRODUCTION}

$\mathrm{A}$ NUMBER OF RESEARCHERS [1-3], being motivated by the fact that "people" are an important factor in software development processes, have argued that one of the

DOĞANCAN KÖSEOĞLU, is with Ekinoks Software, Ankara, Turkey, (email: dogancan.koseoglu@ekinokssoftware.com).

(iD https://orcid.org/0000-0002-4559-280X

OUMOUT CHOUSEINOGLOU, is with the Department of Industrial Engineering Hacettepe University, Ankara, Turkey, (e-mail: uhus@ hacettepe.edu.tr).

(iD https://orcid.org/0000-0002-8513-351X

Manuscript received January 24, 2019; accepted July 30, 2019.

DOI: $\underline{10.17694 / \text { bajece. } 517419}$ most effective methods to improve software developers' performance is focusing on the person and the work environment. In spite the fact that software development processes are controlled with engineering principles and approaches, software developers are still individuals who are affected by the physical and emotional environment and the conditions they work in and around them, and unavoidably their professional and work performance may be influenced by all these $[4,5]$.

Government and public sector institutions and agencies (public institutions) generally meet their software and/or IT requirements by outsourcing these projects to external software development organizations [6]. Moreover, as the number of operations performed by these software systems in the public institutions is high and critical, in order to assure that the software meets the required quality characteristics such as security, reliability and maintainability, numerous employees are employed in the public institutions with titles as "software developer", "software analyst", "software project manager" and "software system manager". These employees can be either civil servants employed directly by the public institution or employees of the software development company which is developing the software in question, who are working within the public institution on a contract in accordance with the agreement reached between the public institution and the software development company. The utilization of external resources as aforementioned is referred to as "onsite outsourcing", where there is a governance structure requiring that all processes are carried out at the client's premises [7], in this case the client being a public institution. Onsite outsourcing in public institutions as defined within the scope of this research is briefly displayed in Figure 1 , where the software developers are shown within the domain of the public institution but are organically associated with the software development company. In the rest of this paper, for sake of consistency, software developers working in public institutions with onsite outsourcing contracts will be briefly referred to as "client side working", client side referring to the public institution.

Onsite outsourcing arrangement offers clients with a greater potential to exert control over the project being developed, especially when the client requires involvement in all steps of the development process, onsite outsourcing is the only solution. Moreover, onsite outsourcing is considered to be advantageous for the client when the client plans to increase 
its workforce with capable employees through augmenting staff, or by bringing in consultants for transferring, sharing and creating knowledge within the organization [8]. However, contrary to these benefits to the client organization, it is observed that such a work agreement between a public institution and a software development organization may lead to highly dissatisfied employees and poor performance.

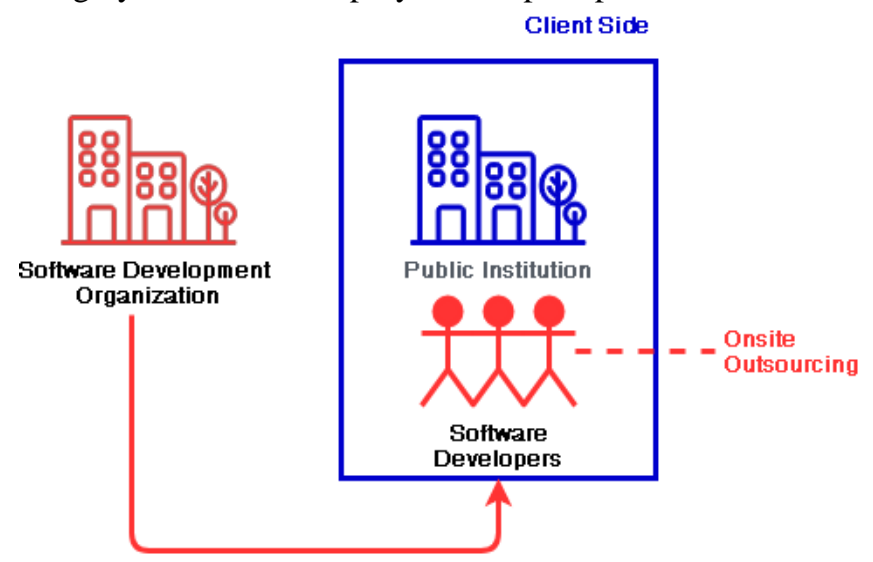

Fig.1. Onsite outsourcing in public institutions

In this study, the factors that affect the productivity, motivation and will to work of software developers working in software projects structured as onsite outsourcing projects are examined, together with the factors that affect the project plan, quality and development schedule of these. The study is a qualitative one and has been conducted by employing the semi-structured interview technique. The employed methodology is the exploratory research, as the aim of the study is to conduct an initial research to better understand the happenings on onsite outsourcing projects in public institutions, so that this initial understanding would facilitate new insights for future research. According to this aim, the research group consists of 15 subjects. The responses collected were analyzed with the use of "qualitative content analysis" technique and the findings were formed and prioritized with the use of the "inductive category formation" technique [9]. The work scheme of the software developers employed in onsite outsourcing projects in public institutions was examined with respect to the following seven research questions (RQ);

$-\mathrm{RQ1}$. What are the reasons for selecting/preferring to work on the client side as part of an onsite outsourcing contract?

- RQ2. What characteristics of client side working affect the productivity of software developers?

- RQ3. What characteristics of client side working affect project quality?

- RQ4. What characteristics of client side working affect the motivation of software developers?

- RQ5. What are the factors that affect the work scheme preference of software developers?

- RQ6. What characteristics of client side working affect project schedule?

- RQ7. What are the important features of being associated to two different organizational hierarchies on software developers working on client side?

The rest of the paper is organized as follows: First, the related work is summarized to identify the gap that this work tries to address. In the third section the details of the research methodology are introduced, and in the fourth section the findings and the key concepts related to each research question are given. The paper ends with a discussion of the findings, contributions and limitations of the present study, threats to validity and suggestions for future work.

\section{RELATED WORK}

Onsite outsourcing has been mostly researched and discussed in connection and as a delivery model of offshore outsourcing and global software development. The common research topics in this area with respect to onsite employees and teams are mostly focusing on knowledge sharing and codification [10-15], work design [16, 17], project cost, project schedule, project cost $[18,19]$ and cultural differences [20]. Betz, Oberweis and Stephan [10] discuss the best practices of knowledge transfer in offshore outsourcing and globally distributed projects, by considering both onsite and offshore project teams. They argue that knowledge transfer is a critical success factor for software development projects that have an onsite and offshore structure, identify problem areas and discuss how onsite teams and offshore teams respond. Regarding knowledge, Kotlarsky, Scarbrough and Oshri [11] examine the coordination of effort between client staff and onsite and offshore vendor personnel, with respect to codification of knowledge as a process that supports coordination. Similarly, Gopal et al. [12] try to reveal the influence of knowledge codification factors that global software development teams designed as offshore and onsite have on the outcomes of the projects. Kumar and Thangavelu [13] examining the relationship of offshore and onsite teams in global software development projects, argue that knowledge sharing and knowledge transfer have a significant association with the project outcome. They argue that knowledge sharing and transfer among offshore and onsite development teams is an important issue and propose a model to address this. Mishra and Mahanty [14] try to identify the knowledge requirements and the effect of knowledge on both onsite and offshore project work division in the outsourcing software industry, concluding that there is a need of higher onsite presence in development projects. Vlaar, van Fenema, and Tiwari [15] investigate how knowledge and experience asymmetries between onsite and offshore team members force them to engage in different acts of sensegiving, sensedemanding, and sensebreaking, concluding that these acts allow them to jointly explore and generate value. Mishra and Sinha [16], by proposing a new metric named as Onsite-Ratio and examining the interrelationships between the elements of work design, project integration challenges, and project performance conclude that managers can actively lower integration glitches by increasing the levels of onsite ratio in software development projects. In a different research, Mishra and Mahanty [17] study manpower dynamics with the purpose of finding good values of onsite-offshore team strength and the number of hours of communication between onsite and offshore teams for smooth transfer of project. Their findings 
show that the project of work transfer should start with initial onsite team strength higher than that of required. Finally, the effects that onsite-offshore employment has on software projects with respect to cost, schedule and quality is investigated by Mishra and Mahanty [18,19].

To the best of our knowledge, no study has been undertaken to understand how software developers are affected while working onsite on the client side in public software projects. The current study is an initial attempt to better understand how the work characteristics, professional decisions and career path of software developers is affected by this employment model. However, the existing literature has guided us on better understanding the specificities of the onsite employment model and how such an exploratory study should be conducted.

\section{METHOD}

\section{A. Qualitative Research and Semi-Structured Interviews}

The current study is designed as a qualitative study. Qualitative studies generally are employed to understand the individual's experiences and how they interpret these experiences [9,21]. Accordingly, interviews have been conducted with a number of employees from the software industry and as their feelings, thoughts and perceptions may differ no limitations have been imposed on their answers and therefore a more extensive content analysis has been conducted.

To conduct the qualitative study, the semi-structured interview technique has been used [22]. Semi-structured interviews are widely used in the software engineering domain in qualitative and/or exploratory studies. In a similar study $\mathrm{Li}$, Ko and Begel [23] have used the semi-structured interviews to discover the interaction types between software engineers and employees from other disciplines and the important characteristics of these interactions. The main rationale for employing semi-structured interviews is to extract detailed information and to allow for further and franker discussion with the participants. Even though the questions are defined and ordered before the interview, they are not asked in the predefined order but rather are being asked as the interview proceeds, typically in an impromptu way.

In the conducted semi-structured interviews, the time-glass model has been employed [24]. In the time-glass model the interviews start with open questions that aim to relax the participant and enhance the sincerity, so that they would answer the interview questions more truthfully and without any reservations. Accordingly, the interviews were concluded by asking more generalized questions. Another reason for employing the time-glass model was that it allowed the interviewer to ask the interview questions in any order, based on the relaxation level of the participant.

\section{B. Content Analysis}

As defined by Haggarty [25] content analysis is a research method used to make generalizations with respect to specific categories of interest by systematically and reliably analyzing the qualitative data collected in the research. In this study qualitative content analysis was employed together with the phenomenological method, which is concerned with the individual's personal perception or account of an event and aims to examine participant's lifeworld in detail by attempting to explore personal experiences [26,27]. In the current study a perspective focusing on the individuals, that is the software developers, and their responses has been chosen. The qualitative content analysis has been implemented by coding the data, identifying the themes in the coded data, by organizing the data codes and themes, and finally by identifying and interpreting the findings [28]. The themes in the coded data were formed and prioritized with the use of the "inductive category formation" technique, by summarizing and analyzing the content to develop categories gradually from the obtained semi-structured interview transcripts [9].

\section{Study Group}

The study group consists of 15 professionals actively employed in the software development industry and being client side working individuals; in detail 10 software developers, one team leader and four project managers. The study participants are employed in 10 different software development organizations, working according to the onsite outsourcing employment structure in 10 different public institutions and in 12 different projects. All participants are residing and working in Ankara, Turkey. The participants have been selected according to the maximum variation / heterogeneous purposive sampling in order to provide a diverse range of cases relevant to client side working software developers. The demographic details of study participants are given in Table I.

TABLE I

STUDY GROUP DEMOGRAPHICS

\begin{tabular}{|c|l|r|r|}
\cline { 3 - 4 } \multicolumn{2}{c|}{} & $\mathbf{N}$ & $\mathbf{\%}$ \\
\hline \multirow{2}{*}{ Gender } & Female & 5 & 33.33 \\
\cline { 2 - 4 } & Male & 10 & 66.67 \\
\hline \multirow{3}{*}{ Title } & Software Developer & 10 & 66.67 \\
\cline { 2 - 4 } & Team Leader & 1 & 6.67 \\
\cline { 2 - 4 } & Project Manager & 4 & 26.67 \\
\hline \multirow{2}{*}{$\begin{array}{c}\text { Graduated } \\
\text { University } \\
\text { Departments }\end{array}$} & Computer Science & 13 & 86.67 \\
\cline { 2 - 4 } & Statistics & 1 & 6.67 \\
\cline { 2 - 4 } & Computer Technology / Information Systems & 1 & 6.67 \\
\hline \multirow{2}{*}{ Experience } & $0-9$ & 9 & 60.00 \\
\cline { 2 - 4 } & $10-19$ & 6 & 40.00 \\
\hline \multirow{2}{*}{$\begin{array}{c}\text { Years Working } \\
\text { in Client Side }\end{array}$} & $1-3$ & 11 & 73.33 \\
\cline { 2 - 4 } & $3-5$ & 4 & 26.67 \\
\hline
\end{tabular}

It has been observed that analogous number of participants have taken part in similar exploratory studies when semistructured interviews are employed: Betz, Oberweis, and Stephan [10] explore the problems and best practices of knowledge transfer in offshore outsourcing by conducting semi-structured interviews with 13 experts, whereas Mishra and Mahanty [14] by conducting semi-structured interviews with 14 experts try to identify the knowledge requirements and the effect of knowledge on both onsite and offshore project work division. Winkler, Dibbern, and Heinzl [20] have conducted interviews with a total of nine project managers to explore the nature of cultural differences in offshore outsourcing and to analyze the relationship between those 
cultural differences and offshore outsourcing success, with respect to onsite-offshore employment model.

\section{Data Collection}

Semi-structured interviews have been used as the data collection technique in order to ease the participants and allow them to give sincerer responses, as they are not as strict and fixed in organization as the structured interviews and not as loose as the fully unstructured interviews. The interviews were conducted face-to-face separately between the period of April 26, 2018 - May 10, 2018. The interview locations were independent locations and were carefully selected such as they would allow the interviewed participant to feel comfortable and relaxed, and consequently to answer the questions frankly. Before the interviews and during them, all required information about the research and the interview questions were given to the participants.

In order to avoid any loss, the responses of the participants were recorded with the use of a voice recording device. The participants were informed that a voice recording device would be used and their consent was obtained before the start of the interviews. Following the conclusion of the interview, the voice recordings were shared with the participants and they were informed that a part or the whole recording may be removed from this research.

\section{E. Data Analysis}

As the first step of the analysis, the interview transcripts were decoded and parsed by the researcher by typing them in a tabular form. In order to ensure the confidentiality of the participants shortened code names were used in the data forms (e.g., MSD1). The forms were filled separately by listening to the voice recordings, were shared individually with the participants with the use of different sharing media (e.g. email, message) in order to avoid any errors while recording the interview responses and were analyzed only after the respondents confirmed the transcripts.

The data extracted from the responses were grouped based on the interview questions and themes were constructed based on the data and the groups, in accordance with the inductive category formation technique. The formed themes were named as "key contents" and were grouped with respect to respondents and interview questions, in order to calculate their frequencies. These key contents were used to identify the factors and factor categories that affect the productivity, motivation and will to work of the respondents, and the factors that affect the plan, quality and development schedule of the project, in accordance with the stated motivation of this study.

The significance and integrity of the findings has been evaluated by the authors consistently. In order to ensure the integrity of the findings, the factors that constitute the themes were checked within themselves and with the other themes, and cross-checked to test if they form a meaningful whole. Finally, the findings were reviewed by other software practitioners and they have been characterized as realistic.

Moreover, during the identification of these key concepts and factors, the positive or negative perception of the respondents regarding each one of these factors was recorded by the interviewer either based on the respondent's statements or by explicitly asking questions. These perceptions are given next to the associated factors in the Findings section as (+) or $(-)$, denoting positive or negative perceptions, respectively.

\section{FINDINGS}

- RQ1. What are the reasons for selecting/preferring to work on the client side as part of an onsite outsourcing contract?

The most common answer (7 responses) by the participants was that they were "appointed by the management of the software development organization to work on client side". This, together with the "fear of losing job" (2 responses) and "conflicts with previous employers and managers" (5 responses) displays that involuntary responses (14, shown with -) are higher than responses that refer to voluntary reasons $(4$, shown with + ). All responses for RQ1 are given in Table II.

TABLE II

RESPONSES FOR RQ1

Company appointment \& compulsory employment

Conflicts with previous employers and management

Wanting to acquire client-side work experience

Fear of being unemployed

Wanting to work at a more corporate organization

- RQ2. What characteristics of client side working affect the productivity of software developers?

The participants have provided a number of characteristics regarding the client side working scheme that affect their productivity, which are given in detail at Table III.

TABLE III

RESPONSES FOR RQ2

\begin{tabular}{|l|c|c|}
\cline { 2 - 3 } \multicolumn{2}{l|}{} & $\mathbf{N}$ \\
\hline Excessive requirements by the client & - & 4 \\
\hline Shorter periods/deadlines given to complete work & - & 4 \\
\hline Lag/tardiness in authorization and approval processes & - & 4 \\
\hline Lack of technical knowledge by the public institution employees & - & 3 \\
\hline Unwillingness of the public institution employees to work & - & 2 \\
\hline Public institution employees abstaining from innovations & - & 2 \\
\hline $\begin{array}{l}\text { The necessity of communicating one-to-one with the public institution } \\
\text { employees }\end{array}$ & - & 2 \\
\hline The corporate organization structure & + & 1 \\
\hline Complexity of the existing legacy systems & - & 1 \\
\hline Dealing directly with the customer & + & 1 \\
\hline Public institution employees preferring to communicate via telephone & - & 1 \\
\hline The existence of outdated technologies & - & 1 \\
\hline Being part of more than one projects at the client side & - & 1 \\
\hline Increased effect of laws and regulations on the developed project & - & 1 \\
\hline Projects in public institutions have a longer development lifecycle & - & 1 \\
\hline The organizational culture of the public institution & - & 1 \\
\hline Negative attitude of the public institution employees & - & 1 \\
\hline The work commitment of the public institution employees & - & 1 \\
\hline The projects have attention getting / spectacular contents & + & 1 \\
\hline Use of subcontractors instead of project team & - & 1 \\
\hline The indifference of the company towards its employees & - & 1 \\
\hline The extensive length of work history with the public institution & + & 1 \\
\hline The experience level of the project manager & + & 1 \\
\hline Working as a team on the client side & + & 1 \\
\hline $\begin{array}{l}\text { The coordination between the software development company and the project } \\
\text { team working at client side }\end{array}$ & - & 1 \\
\hline $\begin{array}{l}\text { Having to work both in the software development company and the client side } \\
\text { (at the same time) }\end{array}$ & - & 1 \\
\hline Working with the highest ranking responsible person at the client side & + & 1 \\
\hline
\end{tabular}

The answers that have been given most are "excessive 
requirements by the client", "shorter periods/deadlines given to complete work" and "lad/tardiness in authorization and approval processes". The majority of these characteristics, as stated by them, are affecting their productivity negatively (34, shown with -) and only few positively (7, shown + ).

- RQ3. What characteristics of client side working affect project quality?

The respondents have stated that "focusing on having the job finished (because of excessive requirements and short deadlines)" and "public institution employees just demand that the work s finished" are the most common factors (both appearing 6 times) that affect project quality. The complete list of these characteristics is given in Table IV with factors that affect the project quality negatively shown with a - (a total of 31 responses) and the ones affecting quality positively shown with a + (a total of 7 responses).

TABLE IV

RESPONSES FOR RQ3

\begin{tabular}{|c|c|c|}
\hline & & \\
\hline $\begin{array}{l}\text { Focusing only on having the job finished because of excessive requirements } \\
\text { and short deadlines }\end{array}$ & - & 6 \\
\hline Public institution employees just demand that the work is finished & - & 6 \\
\hline Public institution employees lacking the knowledge to assess the work quality & - & 4 \\
\hline Using outdated technologies on client side and not risking modernization & - & 4 \\
\hline $\begin{array}{l}\text { Software development in accordance with the requirements of a corporate } \\
\text { organization }\end{array}$ & + & 2 \\
\hline The unwillingness of the project team to work at client side & - & 2 \\
\hline Project team members thinking that their liberty has been compromised & - & 2 \\
\hline Modernization of client side technology is very expensive & - & 2 \\
\hline The necessity of a very solid project plan and analysis & + & 2 \\
\hline The experience level of the project manager & + & 1 \\
\hline Being in an environment isolated from the organizational culture & + & 1 \\
\hline The continuous administrator/manager change in the public institution & - & 1 \\
\hline Public institution employees abstaining from innovations & - & 1 \\
\hline The processes of the public institution are not discussable & - & 1 \\
\hline The project team having few and highly qualified members & + & 1 \\
\hline The hierarchical structure and "ego wars" at public institution & - & 1 \\
\hline Not developing in accordance to the quality standards & - & 1 \\
\hline
\end{tabular}

\section{- RQ4. What characteristics of client side working affect} the motivation of software developers?

Regarding the factors that affect their motivation the respondents mentioned that discussions and quarrels in the public institution work environment (5 responses) mostly upset them. This factor has appeared in the responses to be related with the second most common item ("ego wars", 4 responses). As it can be seen in the results in Table $\mathrm{V}$, the majority of the responses are related with negative factors (a total of 44) and only 7 responses mention factors that affect their motivation positively.

- RQ5. What are the factors that affect the work scheme preference of software developers?

When the factors that affect software developers work scheme preferences were examined, it is observed that three major responses come forward, namely: "career change possibilities" (10), "the contents of the project" (7) and "the existence of hierarchies" (5). Contrary to the responses that were collected for the other research questions, it was observed in Table VI that respondents have mentioned positive factors more (total of 26) with respect to negative factors (9).
RESPONSES FOR RQ4

\begin{tabular}{|l|c|c|}
\cline { 2 - 3 } \multicolumn{2}{l|}{} & N \\
\hline $\begin{array}{l}\text { The discussion (quarrel environment) that exists because of work overload and } \\
\text { time limitations }\end{array}$ & - & 5 \\
\hline The hierarchical structure and "ego wars" at public institution & - & 4 \\
\hline Interferences with the work schedule & - & 3 \\
\hline The bureaucracies at public institution & - & 3 \\
\hline Having to work overtime & - & 3 \\
\hline Public institution employees acting as managers & - & 2 \\
\hline Environmental factors regarding the public institution & - & 2 \\
\hline The software development company decides and plans the onsite working & - & 2 \\
\hline Not having the expected working environment at client side & - & 2 \\
\hline The projects have attention getting / spectacular contents & + & 2 \\
\hline Restrictions on social media, video, music & - & 2 \\
\hline Knowing that client side working is temporary & + & 2 \\
\hline Concern that there is no chance for self-improvement & - & 2 \\
\hline Lack of job satisfaction & - & 2 \\
\hline The continuous administrator/manager change in the public institution & - & 2 \\
\hline The affiliation with the software development organization is just on paper & - & 2 \\
\hline The project plan is a good one & + & 1 \\
\hline The processes take longer to complete & - & 1 \\
\hline More facilities and resources at the software development organization & - & 1 \\
\hline Being held responsible for external bugs / defects & - & 1 \\
\hline Working with a highly qualified team & + & 1 \\
\hline Being motivated with the work & + & 1 \\
\hline Negative attitude of the public institution employees & - & 1 \\
\hline The work commitment of the public institution employees & - & 1 \\
\hline Working with subcontractors & - & 1 \\
\hline Not following project plans or not having plans at all & - & 1 \\
\hline $\begin{array}{l}\text { Having to communicate with public institution employees who lack process } \\
\text { knowledge }\end{array}$ & - & 1 \\
\hline
\end{tabular}

TABLE VI

RESPONSES FOR RQ5

\begin{tabular}{|l|c|c|}
\cline { 2 - 3 } \multicolumn{2}{c|}{} & $\mathbf{N}$ \\
\hline The possibilities of career change with respect to professional capabilities & + & 10 \\
\hline The projects have attention getting / spectacular contents & + & 7 \\
\hline The existence of hierarchies and bureaucracies & - & 5 \\
\hline To feel more comfortable and more free & + & 3 \\
\hline More capable / better colleagues & + & 3 \\
\hline The use of outdated technologies & - & 2 \\
\hline The prospect of starting your own family & - & 2 \\
\hline One-to-one contact with the public institution employees & + & 2 \\
\hline Positive attitude of the managers & + & 1 \\
\hline
\end{tabular}

\section{- RQ6. What characteristics of client side working affect} project schedule?

The study participants have stated that the "intensity of requests and limited time given to complete these requests" is the most common factor (appearing 5 times) that affect the project schedule. As it can be observed from the complete list of these factors in Table VII, the majority are factors that affect the project schedule adversely (22 responses, shown with a -) and only 5 responses mention a positive affect (shown with $\mathrm{a}+$ ).

TABLE VII

RESPONSES FOR RQ6

\begin{tabular}{|l|c|c|}
\cline { 2 - 3 } \multicolumn{2}{l}{} & N \\
\hline Intensity of requests and limited time given to complete these requests & - & 5 \\
\hline $\begin{array}{l}\text { The continuous administrator/manager change in the public institution result } \\
\text { to change in processes }\end{array}$ & - & 3 \\
\hline More or less a project plan is formed & + & 3 \\
\hline Hierarchy and bureaucracy engagement to project & - & 3 \\
\hline The existence of numerous project management approaches & - & 2 \\
\hline Lag/tardiness in authorization and approval processes & - & 2 \\
\hline The software product is associated with other institutions & - & 1 \\
\hline Requests are initiated by more than one sources & - & 1 \\
\hline The move from legacy system to the new system & - & 1 \\
\hline Time for fulfilling requirements & - & 1 \\
\hline Public institution employees' off-topic requests & - & 1 \\
\hline The conformance of the subcontractors to the planned processes & + & 1 \\
\hline Lack of technical knowledge by the public institution employees & - & 1 \\
\hline "Ego wars" between public institution employees & - & 1 \\
\hline Number of in-team employees related to contract & + & 1 \\
\hline
\end{tabular}


- RQ7. What are the important features of being associated to two different organizational hierarchies on software developers?

Regarding the last research question, respondents were asked to state the most important features of being associated to two different organizational hierarchies (one in the software organization and one in the public institution). As it is shown in Table VIII, participants have only mentioned negative features regarding such a working scheme.

TABLE VIII

RESPONSES FOR RQ7

\begin{tabular}{|l|c|c|}
\cline { 2 - 3 } \multicolumn{2}{l|}{} & N \\
\hline Works are assigned by more than one person & - & 6 \\
\hline Requests are initiated by more than one sources & - & 5 \\
\hline "Ego wars" between public institution employees & - & 5 \\
\hline No connection between employees and software development organization & - & 4 \\
\hline $\begin{array}{l}\text { Public institution employees affecting the project manager with their } \\
\text { bureaucratic attitude }\end{array}$ & - & 3 \\
\hline $\begin{array}{l}\text { Public institution employees considering themselves in a higher position } \\
\text { compared to software development organization }\end{array}$ & - & 2 \\
\hline Negative approach of the public institution managers & - & 2 \\
\hline $\begin{array}{l}\text { Interference by public institution and software development organization to } \\
\text { software development process }\end{array}$ & - & 1 \\
\hline $\begin{array}{l}\text { The attitude of public institution employees towards the software development } \\
\text { organization because of their own process lag/tardiness }\end{array}$ & - & 1 \\
\hline Not adopting the public institution culture & - & 1 \\
\hline Not taking into consideration any person or event other than work & - & 1 \\
\hline Irregularities in the software development organization management levels & - & 1 \\
\hline
\end{tabular}

\section{DISCUSSIONS}

\section{A. Validity Threats}

The identified and addressed validity threats of this qualitative and exploratory study are detailed below. The most important construct validity threat is that the participants may have not correctly and fully understood the characteristics and related issues of working on the client side in a public institution, and may have not correctly communicated their thoughts on the subject during the interviews. In order to minimize this, the selected participants were software practitioners having long years of experience working on public institution software projects on the premises of the client. Regarding internal validity and instrumentation, the questions asked to the respondents were formed with respect to the set research questions and they were asked to all participants. However, in accordance to the characteristics of the semi-structured interviews, the questions were not asked in a specific order, but the order would change with respect to the responses of the participants. Moreover, to ensure internal validity the responses of the participants were recorded with the use of a voice recording device. Only after the participant was informed about this, and had consented on the use of this voice recording device the interview was initiated. Following the conclusion of the interview, the collected responses after being processed and the related voice recordings were accordingly shared with the participants and only after receiving their approval were further processed in order to obtain the key concepts. This study was conducted with participants working in Ankara, Turkey and in public institutions located in Ankara, Turkey; therefore, the results cannot be generalized. Yet, in order to provide a diverse range of cases and to obtain diverse responses, the participants have been selected according to the maximum variation / heterogeneous purposive sampling. However, as the study was planned as an exploratory research, the results instead of being generalizable should provide insights for future generalizable studies.

\section{B. Findings}

When the responses for the seven research questions (Table II to Table VIII) are evaluated in overall it is seen that 186 (76.8\%) responses display a negative sentiment and only 56 (23.2\%) of them embody a positive sentiment, an indication that software developers approach and perceive this employment method negatively. Next, we performed word cloud visualization and quantitative readability analysis to see the big picture of the given responses. After removing articles, prepositions and common words that were in the question text (e.g. public, institution, employees), we used wordclouds.com to generate a word cloud showing the focuses of onsite working software developers based on their responses. Figure 2 depicts the word cloud and Table IX lists the 30 most common terms.

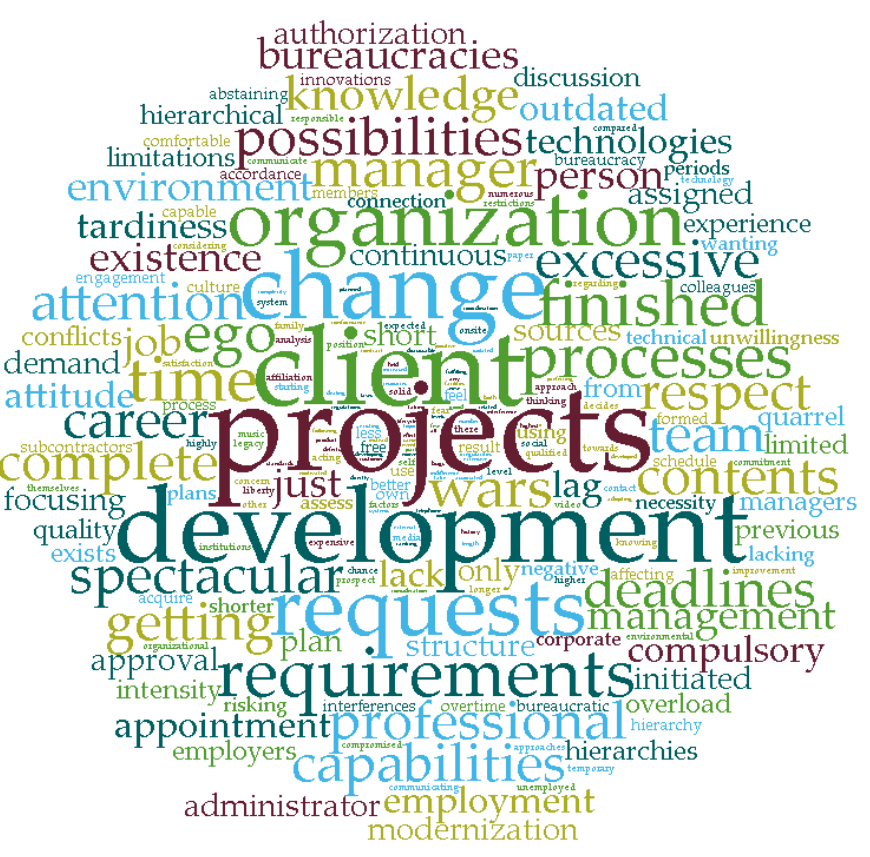

Fig.2. Onsite outsourcing in public institutions

Based on the results from data analysis with respect to the research questions, it is observed that software developers do not prefer to work on the premises of the client, but are forced to work on the client side following the successful bid and winning of the tender by the public institution. With respect to this, the majority of the participants have mentioned that they do experience conflicts with the management of the software organization that they work at and that are currently in search of a new job. However, as they have significant concerns regarding unemployment, when they are confronted with the obligation of having to work on client side in a public institution, they prefer to accept such position offerings even if they do not prefer this work model at all. On the other hand, when asked about the advantageous aspects of client side 
working, the participants after evaluating the overall situation of the software industry, have stated that almost all software companies have contractual agreements with the public institutions.

TABLE IX

THIRTY MOST COMMON TERMS IN THE RESPONSES OF THE STUDY PARTICIPANTS

\begin{tabular}{|l|c|}
\cline { 2 - 2 } \multicolumn{1}{c|}{} & $\mathbf{N}$ \\
\hline projects & 37 \\
\hline client & 24 \\
\hline development & 20 \\
\hline change & 19 \\
\hline requests & 17 \\
\hline organization & 16 \\
\hline requirements & 13 \\
\hline processes & 12 \\
\hline finished & 12 \\
\hline time & 12 \\
\hline
\end{tabular}

\begin{tabular}{|l|c|}
\cline { 2 - 2 } \multicolumn{1}{c|}{} & $\mathbf{N}$ \\
\hline manager & 11 \\
\hline wars & 11 \\
\hline ego & 11 \\
\hline possibilities & 10 \\
\hline professional & 10 \\
\hline capabilities & 10 \\
\hline spectacular & 10 \\
\hline excessive & 10 \\
\hline deadlines & 10 \\
\hline attention & 10 \\
\hline
\end{tabular}

\begin{tabular}{|l|r|}
\cline { 2 - 2 } \multicolumn{1}{c|}{} & $\mathbf{N}$ \\
\hline complete & 10 \\
\hline contents & 10 \\
\hline getting & 10 \\
\hline respect & 10 \\
\hline career & 10 \\
\hline team & 10 \\
\hline knowledge & 9 \\
\hline bureaucracies & 8 \\
\hline environment & 8 \\
\hline management & 8 \\
\hline
\end{tabular}

It is observed that the software developers have different views with respect to their productivity when working on client side projects. The participants have stated that works are assigned to them frequently and that assigned works have short completion times, thus they focus only on finishing the assigned work item on time, without having the opportunity to develop new ideas or approaches with respect to the problem at hand. Especially the participants working as project managers on projects developed on the client side have mentioned that the processes on the public institutions are slow, they have to exert too much effort and allocate too much time in order to obtain the required permissions and authorizations, thus they believe that they are becoming less productive.

On the other hand, when the results regarding the responses of the software developers on project quality are analyzed, it can be seen that there are similarities with the answers given for the productivity aspects in client side working. They have stated that the quality of a software project depends on the amount of time spent for reasoning, contemplation and rigorous planning; however, they generally do not have time for such an approach and they need to finish numerous work items in a very short time. This in return, as they have mentioned, leads to the project team members forsaking quality for the sake of finishing tasks in time. Moreover, it has been identified as a recurring observation that the staff at the public institution does not control the quality of the project but only focuses on the completion of work packages and tasks. The participants believe that the high turn-over rate of public servants and the apprehension they feel regarding the rapid changing processes is the major reason for this behavior.

It has been observed that for the most part of their work experiences the motivation of the participants is low. They have mentioned different explanations for this; however, the intense work schedule and the expectation of completing urgent and pressing tasks are the predominant reasons. The participants consider working on the client side partially as being unsuccessful and as having to keep up continuously with deadlines, findings that are consistent with the facts in literature $[4,5,29]$. Moreover, the interpersonal relationships and team dynamics in the client side are generally different from the ones that the participants are accustomed to at the software development organization. The participants have stated that these new interpersonal relationships, blended with strict and structured hierarchical rules and bureaucracies, hinder the relaxed, resilient and high-motivated work of the software developers.

Almost all participants to this study have clearly stated that they would prefer to work on the premises of the software company instead of the client. Most of them have mentioned that their professional skills and competencies deteriorate when working on the client side, the possibility that the work tasks would get standardized is higher and that they generally do not add or implement new technologies but only solve problems by developing new algorithms. However, they mention that when working on the software company they have the opportunities to work with new technologies, testing and implementing them in projects; something which is not possible on the client side in public institutions as the software generally is already a being used system. The majority of the participants have stated that they would accept to work on the client side if the contents of the project are challenging and if the project is about an incoming software. Furthermore, some of the participants have stated that the hierarchical structure and the bureaucracy in the public institutions affect them negatively, and that they would prefer to work in a friendlier environment with coworkers and supervisors who approach them positively and supportively.

The participants have stated that they experience a number of issues regarding project planning, duration assignment to tasks and management of the projects when working at the client side. According to them the main reason for this is that the supervisors and employees in the public institutions generally comprehend and use project management concepts differently and almost always want their requests to be fulfilled immediately. Moreover, it has been mentioned during the interviews that there is a high turn-over rate in the public institutions and that managers change in an unpredictable way, with new managers bringing conflicting requirements and the necessity to plan the processes from scratch. Another important finding was that the participants perceive the technical knowledge and skills of the public institution employees to be inadequate, commenting that most of the time they are required to explain and train them regarding new technologies, hardware and programming languages.

Lastly, it has been observed from the interview texts that the assignment of the tasks from a single authority point has a positive effect on the participants. As working on the client side is already difficult because software developers are in an environment different from what they are used at, conflicts between the public institution employees result to changes in project plans that hinder the work. According to the participants, working under two different hierarchies results to being assigned work by both the public institution and the software company managers, whereas ideally the software developer should only be assigned work by the direct supervisor. 


\section{CONCLUSION}

As a result of this exploratory study it can be argued that the participants prefer to work with qualified, having positive attitude and favorable coworkers and managers, in a relaxed work environment isolated from hierarchical and bureaucratic structures, on projects that employ cutting edge technologies and follow the widely accepted project management standards.

With respect to this and based on the findings of the research questions, a future study employing structured tools like questionnaires has been planned to analyze in depth the software developers and software teams working on the client side, but also the characteristics of software projects developed with this employment model. Moreover, to better understand the dynamics and structure of the onsite outsourcing arrangement in public institutions for software development, not only employees affiliated with the developer side but also employees and managers from the client side are considered to be participants of the planned future study.

\section{REFERENCES}

[1] B. W. Boehm, P. N. Papaccio, "Understanding and controlling software costs". IEEE transactions on software engineering, 14 (10), 1988, pp. 1462-1477.

[2] A. Cockburn, J. Highsmith ,"Agile software development, the people factor". Computer, 34(11), 2001, pp. 131-133.

[3] S. de Barros, et al., "A review of productivity factors and strategies on software development", In 2010 Fifth International Conference on Software Engineering Advances (ICSEA), August 2010, pp. 196-204.

[4] R. Ilies, T. A. Judge, "Understanding the dynamic relationships among personality, mood, and job satisfaction: A field experience sampling study". Organizational behavior and human decision processes, 89(2), 2002, pp. 1119-1139.

[5] D. Graziotin, X. Wang, P. Abrahamsson, "Happy software developers solve problems better: psychological measurements in empirical software engineering". PeerJ, 2014, p. e289

[6] P. Mohagheghi, M. Jørgensen, "What Contributes to the Success of IT Projects? An Empirical Study of IT Projects in the Norwegian Public Sector". Journal of Software, 12(9), 2017, pp. 751-759.

[7] J. H. Lim, V. J. Richardson, R. W. Zmud, "Value implications of IT outsourcing contextual characteristics". Unpublished article, 2007.

[8] T. Kremic, O. Icmeli Tukel, W. O. Rom. "Outsourcing decision support: a survey of benefits, risks, and decision factors" Supply Chain Management: An International Journal 11.6, 2006, pp. 467-482.

[9] P. Mayring, Qualitative content analysis: theoretical foundation, basic procedures and software solution, 2014.

[10] S. Betz, A. Oberweis, R. Stephan. "Knowledge transfer in offshore outsourcing software development projects: An analysis of the challenges and solutions from German clients." Expert Systems 31.3, 2014, pp. 282-297.

[11] J. Kotlarsky, H. Scarbrough, I. Oshri. "Coordinating Expertise Across Knowledge Boundaries in Offshore-Outsourcing Projects: The Role of Codification." MIS Quarterly 38.2, 2014, pp. 607-627.

[12] J. Gopal, et al. "Towards identifying the knowledge codification effects on the factors affecting knowledge transfer effectiveness in the context of GSD project outcome." Emerging ICT for Bridging the FutureProceedings of the 49th Annual Convention of the Computer Society of India (CSI) Volume 1. Springer, Cham, 2015.

[13] S.A. Kumar, A. Kumar Thangavelu. "Factors affecting the outcome of Global Software Development projects: An empirical study." 2013 International Conference on Computer Communication and Informatics. IEEE, 2013.

[14] D. Mishra, B. Mahanty. "Business knowledge requirements and onsite offshore work division in Indian software outsourcing projects." Strategic Outsourcing: An International Journal 8.1, 2015, pp. 76-101.

[15] P. Vlaar, P.C. van Fenema, V. Tiwari. "Cocreating understanding and value in distributed work: How members of onsite and offshore vendor teams give, make, demand, and break sense.” MIS quarterly 32.2, 2008, pp 227-255.
[16] A. Mishra, K. K. Sinha. "Work design and integration glitches in globally distributed technology projects." Production and Operations Management 25.2, 2016, pp. 347-369.

[17] D. Mishra, B. Mahanty. "Study of maintenance project manpower dynamics in Indian software outsourcing industry." Journal of Global Operations and Strategic Sourcing 12.1, 2019, pp. 62-81.

[18] D. Mishra, B. Mahanty. "The effect of onsite-offshore work division on project cost, schedule, and quality for re-engineering projects in Indian outsourcing software industry." Strategic Outsourcing: An International Journal 7.3, 2014, pp. 198-225.

[19] D. Mishra, B. Mahanty. "A study of software development project cost, schedule and quality by outsourcing to low cost destination." Journal of Enterprise Information Management 29.3, 2016, pp. 454-478.

[20] J.K. Winkler, J. Dibbern, A. Heinzl. "The impact of cultural differences in offshore outsourcing - Case study results from German-Indian application development projects." Information Systems Frontiers 10.2, 2008, pp. 243-258.

[21] D. J. Bluhm, et al., "Qualitative Research in Management: A Decade of Progress", Journal of Management Studies,2011 p. 48.

[22] C. Robson, Real World Research. Oxford: Blackwell, 2002

[23] P. L. Li, A. J. Ko, A. Begel, "Cross-disciplinary perspectives on collaborations with software engineers". In 2017 IEEE/ACM 10th International Workshop on Cooperative and Human Aspects of Software Engineering (CHASE), 2017, pp. 2-8

[24] P. Runeson, M. Höst, "Guidelines for Conducting and Reporting Case Study Research in Software Engineering", Empirical software engineering, 14(2), 2008

[25] L. Haggarty, "What is content analysis?" Medical Teacher 18.2, 1996, pp. 99-101.

[26] V. Eatough, J. A. Smith. "Interpretative phenomenological analysis.", The Sage handbook of qualitative research in psychology, 2008.

[27] R. H. Hycner, "Some guidelines for the phenomenological analysis of interview data." Human studies 8.3, 1985, pp. 279-303.

[28] Ü. Akyuz, "Assessment of European Union Funded Projects Finalised by the Ministry of National Education based on the Opinions of Administrators and Experts", TED Education and Science, 2015, pp. 199-201.

[29] Y. Lin, W. Mckeachie, Y. Kim, "College Student Intrinsic and/or Extrinsic Motivation and Learning". Learning and Individual Differences, 2003, pp. 251-258.

\section{BIOGRAPHIES}

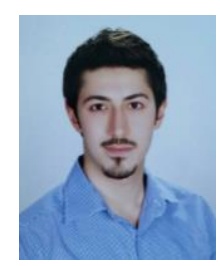

DOĞANCAN KÖSEOĞLU was born in Ankara, Turkey, in 1992. He received his B.S. degree in Computer Engineering from Selçuk University, Konya, Turkey, in 2015 and his M.S. degree in Engineering Management from Hacettepe University, Ankara, Turkey in 2018. Currently he is working as a software engineer at Ekinoks Software, Ankara. His research interests include processes of software lifecycle management and software project planning.

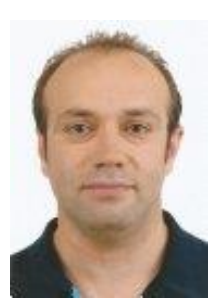

OUMOUT CHOUSEINOGLOU received his B.S. degree in Business Administration and M.S. and Ph.D. degrees in Information Systems from Middle East Technical University (METU) in 2000, 2004 and 2012 respectively. Since 2013, he has been with the Department of Industrial Engineering, Hacettepe University, Turkey. His current research and teaching interests include software engineering, software project management, cloud computing, data communications and networking, and management information systems. 